\title{
PRODUÇÃO INDUSTRIAL DE HORMÔNIOS ESTEROIDES
}

Erlon Lopes PEREIRA ${ }^{1}$

Anna Luísa Ribeiro MIGUEL ${ }^{2}$

\author{
${ }^{1}$ Setor de Engenharia Química. Departamento de Química. Universidade Federal de Viçosa. Campus Viçosa-MG. \\ erlonlopes@gmail.com \\ ${ }^{2}$ Setor de Engenharia Química. Departamento de Química. Universidade Federal de Viçosa. Campus Viçosa-MG. \\ anna.miguel@ufv.br
}

Recebido em: 13/07/2016 - Aprovado em: 07/11/2017 - Disponibilizado em: 30/12/2017

\begin{abstract}
RESUMO:
Esteroides são compostos orgânicos que possuem em comum o núcleo esteroide, formado por três anéis com seis átomos de carbono e por um anel com cinco átomos de carbono. Hormônios esteroides são compostos esteroides produzidos pelo organismo e possuem atividades reguladoras do metabolismo. Dada a importância destes compostos para a manutenção da vida, hormônios esteroides sintéticos têm sido produzidos para suprir possíveis déficits do organismo. A produção industrial dos hormônios sintéticos é baseada na biotransformação do substrato escolhido provocada por microrganismo específico através de processos fermentativos. Alguns compostos causam danos ambientais e tecnologias devem ser desenvolvidas para sanar possíveis problemas. As expectativas do setor giram em torno do desenvolvimento de tecnologias de imobilização de microrganismos, de sistemas de fase reversa e do DNA recombinante.

Palavras-chave: hormônios esteroides sintéticos; $17 \alpha$-etinilestradiol; imobilização de microrganismos.
\end{abstract}

\begin{abstract}
:
Steroids are organic composts that have in common the steroid nucleus, which is compound by three rings containing six carbon atoms and by one ring containing five carbon atoms. Steroids hormones are steroids composts produced by organism and they have metabolic regulator activities. These substances show a huge importance that justify the industrial production of synthetic steroids hormones. These synthetics composts are utilized to supply organism deficits. The industrial production is based on substrate biotransformation caused by a specific microorganism in the propicious conditions for the fermentative process. Some compounds induce damage in the environment and technologies that solve these problems should be developed. There are some expectation regarding the development of the area: immobilization of microorganism, reverse phase system and recombinant DNA technology.
\end{abstract}

Keywords: synthetic steroids hormones; $17 \alpha$-etinilestradiol, immobilization of microorganism.

\section{INTRODUÇÃO}

Hormônios esteroides são compostos orgânicos sintetizados pelo organismo, como aqueles produzidos pelas glândulas suprarrenais e pelas glândulas sexuais. Possuem diversas funções de controle do metabolismo (equilíbrio hidroeletrolítico e regulação de hidratos de carbono e proteínas), atuam no desenvolvimento de características sexuais, estão relacionados com o crescimento e possuem ação anti-inflamatória, como diz Soares (2013). A deficiência de algum desses hormônios pode desencadear doenças, como o desenvolvimento da osteoporose destacado por Amadei et al. (2006).

Dada a importância destes compostos para o funcionamento do organismo, a produção de hormônios esteroides sintéticos tornou-se 
interessante. Estes compostos, segundo Soares (2013), têm sido utilizados pela medicina no combate de processos inflamatórios, no trato de doenças, por exemplo hipogonadismo e asma brônquica, e de crises alérgicas, na reposição hormonal perante alguma deficiência e como contraceptivos. São também utilizados no tratamento de inflamação ocular, de doenças colagenosas, de distúrbios neuromusculares e na manutenção cardiovascular, como apresentado por Antonow et al. (2007).

Sempre em busca do processo produtivo mais economicamente viável, o processo de produção de esteroides está em constante estudo. O microrganismo mais adequado e eficiente, o substrato de menor custo que fornecerá o produto desejado, a rota de transformação mais econômica e o processo fermentativo mais rentável são tópicos analisados na busca do processo produtivo ideal, como abordado por Oliveira e Mantovani (2009). Todavia, aqueles que vem sendo realizados estão protegidos através de registro de patente devido ao seu alto valor comercial, dificultando a busca de dados e conhecimento do processo.

Visto o exposto, este trabalho tem como objetivo apresentar uma revisão bibliográfica, utilizando os trabalhos disponíveis na literatura científica (portais consultados: Science Direct, Scielo, Portal de Periódicos da Capes), ao classificar hormônios esteroides, enfatizar os processos biotecnológicos de produção dos hormônios sintéticos e destacar os efeitos destes compostos no meio ambiente. Apresenta-se, ainda, expectativas para a produção industrial destes compostos através de processos biotecnológicos.

\section{REVISÃO BIBLIOGRÁFICA}

\subsection{ESTEROIDES E HORMÔNIOS ESTEROIDES}

Nelson e Michael (2014) conceituam esteroides como compostos orgânicos que possuem em sua estrutura um núcleo esteroide (Figura 1). Um núcleo esteroide é formado por quatro anéis fundidos entre si, sendo que três deles possuem seis átomos de carbono e um, cinco átomos de carbono. Este núcleo é denominado de ciclo pentanoperidrofenantreno.

Figura 1- Núcleo esteroide:

ciclopentanoperidrofenantreno

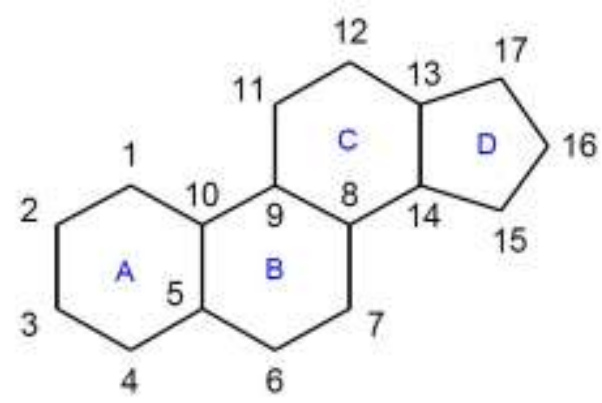

Fonte: Soares, 2013

De acordo com Voet (2013), o esteroide mais abundante nos animais é o colesterol (Figura 2), também classificado 
como esterol devido ao grupo $\mathrm{OH}$ na posição C3 e pela cadeia alifática lateral ramificada na posição C17. O colesterol é um importante componente das membranas nas células eucarióticas e é o precursor de hormônios esteroides.

Figura 2 - Estrutura molecular do colesterol

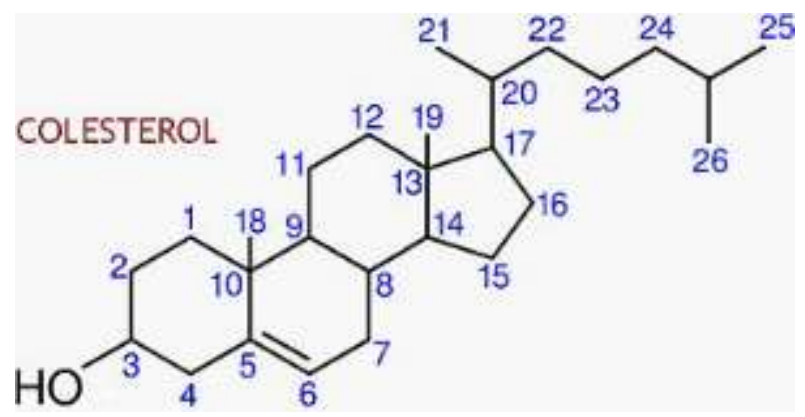

Fonte: Patricio, 2011

Os hormônios esteroides são com

Redondo

(2007)

progestógenos, corticosteroides, androgênios e estrogênios. Sendo que, segundo Antonow et al. (2007), os corticosteroides são subdivididos em glicocorticoides e mineralocorticoides.

De acordo com Vigo et al. (2011), os progestógenos são hormônios esteroides e a progesterona é o único progestógeno natural. As progestinas são progestógenos sintéticos, geralmente sintetizadas a partir de moléculas de progesterona e testosterona. Segundo Rathke et al. (2001), os progestógenos sintéticos são utilizados como contraceptivos, associados ou não com estrogênios. A Tabela 1 apresenta um resumo das principais progestinas e seus precursores.

classificados em quatro categorias, de acordo

Tabela 1 - Principais progestógenos sintéticos

\begin{tabular}{lll}
\hline & \multicolumn{1}{c}{ Progesterona } & \\
\hline $\begin{array}{l}\text { Derivados da } 17 \alpha- \\
\text { hidroxiprogesterona }\end{array}$ & $\begin{array}{l}\text { Derivados da 19- } \\
\text { nortestosterona }\end{array}$ & $\begin{array}{l}\text { Derivados da } 17 \alpha- \\
\text { espirolactona }\end{array}$ \\
\hline dihidroprogesterona & desogestrel & drospirenona \\
medroxiprogesterona & gestodeno & \\
& levonorgestrel & \\
& linestrenol & \\
& nomegestrol & \\
&
\end{tabular}

Fonte: Fernandes, 2015

Antonow et al. (2007) classificam os glicocorticoides como hormônios esteroides sintetizados no córtex da glândula adrenal que agem no controle do metabolismo dos carboidratos e das proteínas, sendo o cortisol o exemplo de glicocorticoide natural. Os glicocorticoides sintéticos mais conhecidos são: blecometasona,

betametasona, dexamentasona, metilprednisolona, prednisolona e triancinolona. Segundo Bavaresco et al. (2005), estes compostos possuem poderosa ação anti-inflamatória e imunossupressora, são utilizados em reposição hormonal, no tratamento 
antialérgico e, combinado com outros medicamentos, no tratamento de câncer.

Outro grupo de hormônio esteroide são os mineralocorticoides, caracterizados por Fernandes-Rosa e Antonini (2007) como reguladores de água e de sódio, além de exercerem efeitos sobre o sistema nervoso central e sobre o sistema cardiovascular.

Os autores ainda definem a aldosterona como o mais importante mineralocorticoide natural que, segundo Miranda e Fontoura (2013), é produzida no córtex da suprarrenal e tem papel indispensável no controle eletrolítico e da pressão arterial. Sobre o representante sintético deste grupo de hormônios esteroides, Wanjgarten et al. (2007) citam a fludrocortisona, uma vez que esta apresenta propriedades características deste grupo.

De acordo com Reis Filho et al. (2006), os hormônios esteroides estrogênio e androgênio são também conhecidos como hormônios sexuais femininos e masculinos, respectivamente, e, de acordo com Macêdo e Fernandes (2003), eles são responsáveis pelas mudanças nas características sexuais primárias e secundárias durante a puberdade.

Ignacio et al. (2009) apresentam três tipos de estrogênios naturais: 17 $\beta$-estradiol, estrona e estriol, sendo o $17 \beta$-estradiol o que possui maior atividade estrogênica. De acordo com Pinto e Chapeta (1995), os estrogênios têm como função controlar o ciclo menstrual, aumentar a deposição de gordura, promover as características sexuais femininas e ainda exercem um efeito protetor dos ossos, melhorando a absorção de cálcio e reduzindo sua remoção dos ossos.

De acordo com Giacomini e Mella (2006), em mulheres na menopausa, a deficiência de estrogênio pode acentuar a perda óssea causando osteoporose, o que torna necessária a reposição deste hormônio. Segundo Zahar et al. (2005), mulheres na menopausa podem sofrer alterações fisiológicas, como suores noturnos, ondas de calor, incontinência urinária, e alterações comportamentais, como depressão, insônia, irritabilidade e mudanças de humor. Neste contexto, a terapia de reposição hormonal apresenta-se como uma opção de tratamento e prevenção destes sintomas.

Os principais estrogênios sintéticos, segundo Pardini (2014), são o dietiletilbestrol, etinilestradiol, mestranol e o quinestrol. Estes compostos são também utilizados como contraceptivos, como diz Fernandes (2015), associados ou não a progestógenos.

De acordo com Rocha et al. (2007), os androgênios, além de serem responsáveis pelo desenvolvimento e manutenção das características sexuais masculinas, possuem importante função anabólica relacionada ao aumento da massa muscular por favorecer a síntese proteica. Segundo Silva et al. (2002), o principal hormônio androgênio é a testosterona, embora os testículos também excretem em pequenas quantidades desidroepiandrosterona (DHEA), androstenediol e 5- $\alpha$-diidrotestosterona. 
Silva et al. (2002) afirmam que os esteroides anabólicos androgênicos sintéticos são derivados da testosterona e caracterizamse por suas ações anabólicas (crescimento muscular) serem superiores às suas ações androgênicas (masculinização). De acordo com Silva et al. (2002) e Macedo et al. (1998), os androgênios são utilizados no tratamento clínico de deficiências naturais de andrógenos, na recuperação de cirurgias e atrofias musculares, tratamento da osteoporose, do câncer de mama e de anemias; também têm sido usados no tratamento de pacientes portadores de HIV.

Macedo et al. (1998) destacam o uso destas substâncias por atletas e praticantes de atividades físicas para que possam melhorar o desempenho físico, bem como ganhar massa muscular. Porém, como abordado por Abrahin e Sousa (2013), o uso indiscriminado e abusivo de esteroides anabolizantes podem expor o usuário a efeitos colaterais como alterações de humor, agressividade, danos ao fígado, aumento da pressão arterial, diminuição da função do miocárdio, impotência e infertilidade.

A Figura 3 apresenta um esquema simplificado da biossíntese de alguns esteroides, apresentando um exemplo de cada grupo de hormônios esteroides abordados acima.
Figura 3 - Biossíntese de hormônios esteroides

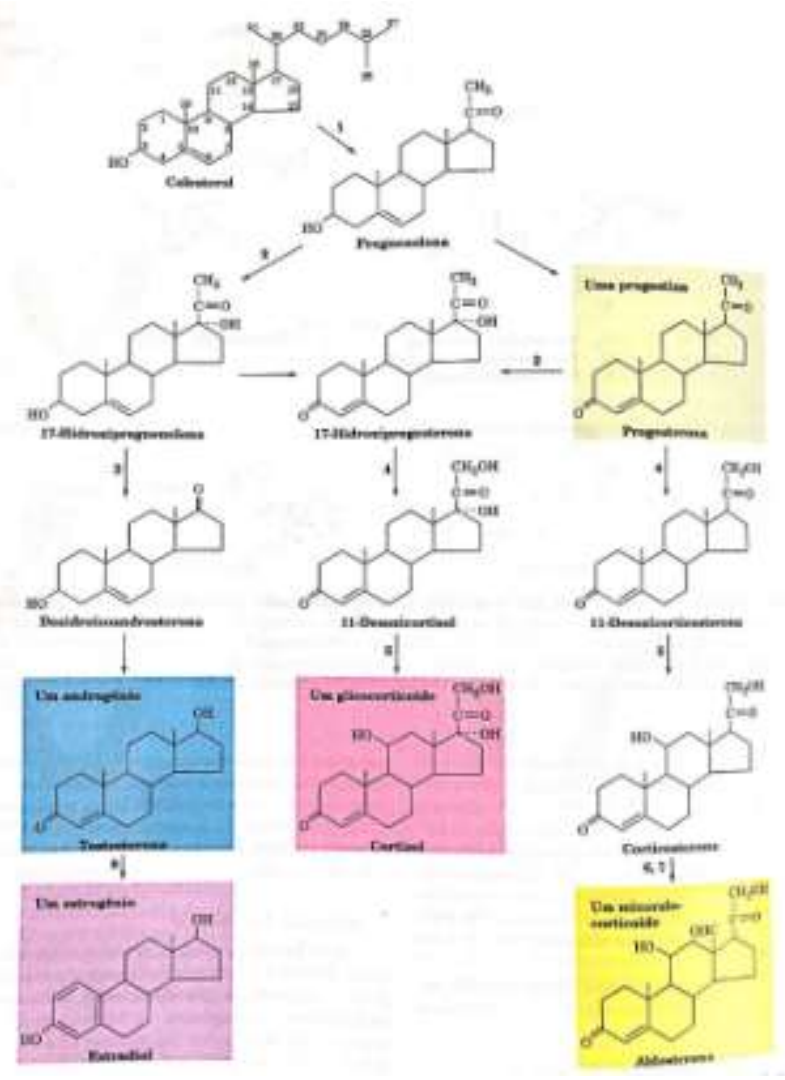

Fonte: Voet, 2013

Visto a importância destes compostos para o bom funcionamento das atividades vitais do organismo e a aplicação de alguns hormônios esteroides sintéticos, é possível compreender $\mathrm{o}$ interesse industrial na produção destes compostos. Para tanto, é necessário ter conhecimento sobre os processos produtivos, visando tomadas de decisão com embasamento técnico.

\subsection{PRODUÇÃO INDUSTRIAL DE ESTEROIDES}

O processo biológico de transformação de um composto orgânico em um produto recuperável, utilizando a catálise por enzimas celulares para pequenas 
modificações no composto, é chamado de biotransformação, como diz Oliveira e Oliveira (2012).

Castro et al. (2004) destacam como vantagens das biotransformações em relação aos processos químicos o fato de serem realizadas a temperaturas brandas, entre 30 e $70{ }^{\circ} \mathrm{C}$, e pressão atmosférica, por apresentarem elevadas conversões e alta especificidade, produzindo um único isômero do produto. Segundo Oliveira e Oliveira (2012), além destas vantagens apresentadas, as biotransformações não geram resíduos tóxicos. Como desvantagem, eles citam a perda da atividade enzimática e os custos mais elevados.

De acordo com Lima et al. (2005), o processo de produção de esteroides consiste em uma biotransformação, na qual o microrganismo em questão transforma o substrato no esteroide de interesse, ou em um intermediário, a partir da ação de suas enzimas.

\subsubsection{Microrganismos utilizados na produção de hormônios esteroides} (HE)

Em processos de biotransformação, os catalisadores bioquímicos (microorganismos vivos íntegros ou material biológico, como anticorpos e enzimas isoladas ou em células) realizam interconversões da estrutura química ou modificações específicas na matéria prima escolhida, ou seja, no substrato, como descrito por Castro et al. (2004).

Segundo Lima et al. (2005), na produção de esteroides, os microrganismos atuam na biotransformação do substrato utilizado convertendo-o no produto final de interesse ou em algum intermediário que será posteriormente tratado até obter o produto de interesse. Para isso, existem dois tipos principais de transformações: hidroxilação e desidrogenação.

Em reações de hidroxilação, o grupo hidroxila $(\mathrm{OH})$ atua como nucleófilo ou eletrófilo e ataca moléculas orgânicas acoplando-se em anéis aromáticos ou em duplas ligações, substituindo um átomo de hidrogênio, como descreve Aguiar et al. (2007). Na biotransformação de esteroides, o oxigênio da hidroxila é proveniente do oxigênio molecular e não da água, mantendo a configuração estereoquímica da molécula, segundo Lima et al. (2005). A principal reação de hidroxilação na produção de compostos esteroidais é a 11- $\alpha$-hidroxilação.

Lima et al. (2005) definem desidrogenação como reações em que há perda de hidrogênio ligado a um carbono do núcleo esteroide com formação de dupla ligação. A reação de desidrogenação mais comum na produção de esteroides é a desidrogenção $\mathrm{C} 1$.

Lima et al. (2005) descrevem que diversos tipos de microrganismos podem ser utilizados no processo de biotransformações para a produção de HE. Os autores afirmam 
que os fungos filamentosos são aqueles que possuem maior importância, seguidos dos actinomicetos e de algumas bactérias.

De acordo com os autores, Rhizopusarrhizus e Rhizopusnigricans são fungos que atuam na 11- $\alpha$-hidroxilação da progesterona, convertendo-a no intermediário 11- $\alpha$-hidroxiprogesterona. Este intermediário poderá sofrer a ação de outros microrganismos, como a desidrogenação por Septomyxaaffinis, resultando em esteroides de interesse, como a prednisolona e prednisona. Podem também sofrer alterações químicas para obtenção do produto de interesse, como é o caso da produção de hidrocortisona e cortisona.

\section{Fungos}

como

\section{Cunninghamellablakesleeana}

$\mathrm{e}$

Curvularialunata também são capazes de converter substratos, como a progesterona, em esteroides de interesse, como a hidrocortisona, de acordo com os autores.

Os autores também apresentam Septomyxaaffinis e Arthrobacter simplex como microrganismos utilizados em transformações de desidrogenação, como é o caso da hidrocortisona convertida em 16- $\alpha$ hidroxilada através de reação química e desidrogenada pela ação da Arthrobacter simplex em triamcinolona

$\mathrm{Na}$ Figura 4, é possível observar que diferentes tipos de substratos podem ser utilizados para produção dos corticosteroides. Como observado, a obtenção do produto final a partir do substrato se dá através de etapas químicas, de processos de biotransformações realizados por diferentes microrganismos ou ainda da combinação de reações químicas e biotransformações.

Figura 4 - Esquema de produção de corticosteroides
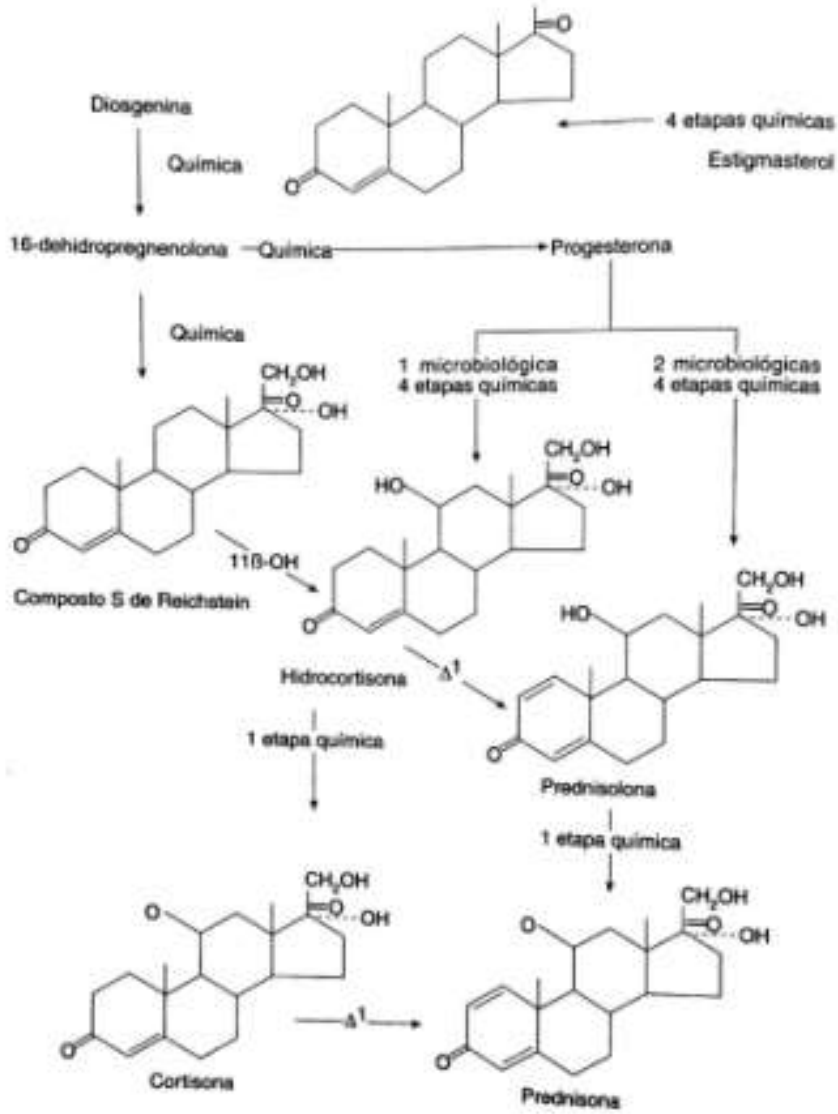

Fonte: Lima et al., 2005

Os autores explicam ainda que o mecanismo de ação destes microrganismos tem objetivo destoxificante, ou seja, as transformações são realizadas para neutralizar substâncias tóxicas aos próprios microrganismos. Ressaltam, ainda, que o meio de cultura adequado para o crescimento destes microrganismos deve conter fonte de carbono e fonte de nitrogênio. Como fonte de carbono, pode-se utilizar melaço, solução de glicose e de outros açúcares, e como fonte de 
nitrogênio, extrato de levedura, água de milho ou compostos minerais.

A escolha do microrganismo deve ser feita de acordo com a escolha do substrato, de forma que ambos sejam compatíveis. Sendo assim, é de fundamental importância para o processo de produção de HE o estudo do substrato a ser utilizado.

\subsubsection{Substratos utilizados na produção de HE}

De acordo com Lima et al. (2005), os substratos utilizados na produção de esteroides podem ser de origem microbiana, vegetal ou animal, sendo que aqueles provenientes de vegetais têm maior importância devido ao baixo custo de sua obtenção e a grande concentração em que são encontrados. Alguns destes substratos encontrados em vegetais são o estigmasterol e a diosgenina.

O estigmasterol, segundo os autores, é encontrado no feijão de soja e convertido em progesterona. Feijão de soja é o nome dado aos grãos de soja que podem ser consumidos na alimentação, segundo Carvalho et al. (2002). Também no feijão de soja, podem ser encontrados o $\beta$-sitosterol e o campesterol, que dão origem a dois importantes intermediários: androstenediona e androstadienediona

A diosgenina, encontrada no barbasco mexicano, uma planta natural do México segundo Hinke (2008), pode ser utilizada na síntese de androgênios e estrogênios. Porém seu elevado custo tem favorecido outros substratos, como o ácido desoxicólico obtido na bile bovina.

O colesterol, precursor de todos os hormônios esteroides, pode ser obtido na cera de lã, e transformado nos intermediários androstenediona e androstadienediona, assim como o $\beta$-sitosterol e o campesterol também podem ser transformados nestes intermediários.

A Figura 5 apresenta a estrutura do estigmasterol, da diogesnina, do colesterol, do $\beta$-sitosterol e do ácido desoxicólico. Todos estes compostos são utilizados como substratos na produção de hormônios esteroides.

Figura 5 - Alguns substratos para produção de hormônios esteroides
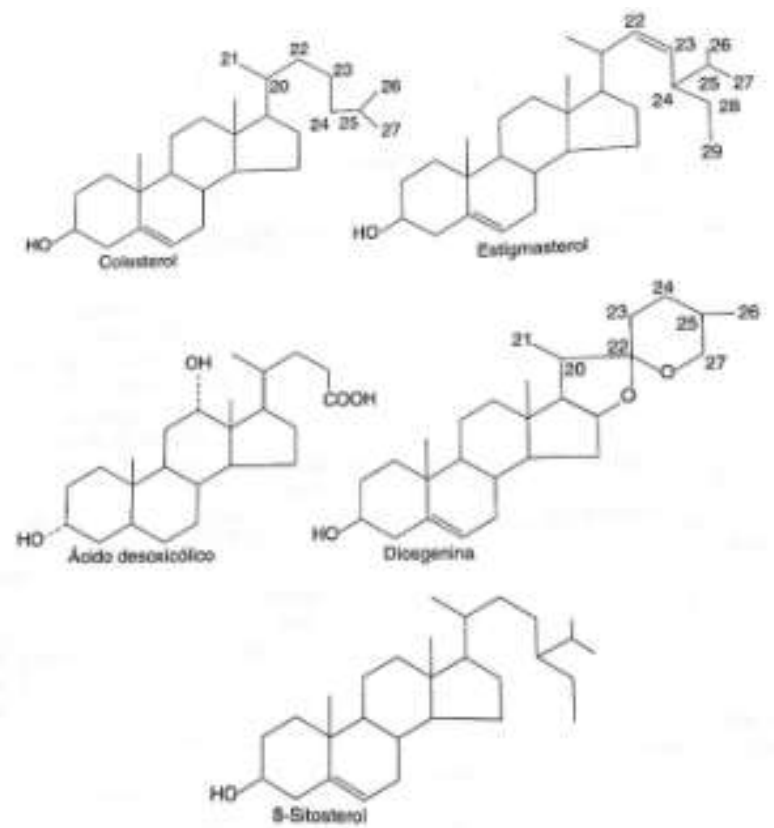

Fonte: Lima et al., 2005 
Após a seleção do microrganismo e do substrato ter sido feita, é necessário conhecer as condições de crescimento celular e de processo para que a maior eficiência da conversão do substrato no produto de interesse a partir de ação do microrganismo seja atingida.

\subsubsection{Principais processos de fermentação para produção de esteroides}

Segundo Lima et al. (2005), existem dois processos principais de produção industrial de esteroides: processo de fermentação direta, que possui apenas uma fase e o substrato é adicionado ao meio de cultura, e o processo de fermentação dupla, que possui duas fases.

Processo de fermentação direta: $O$ processo acontece em fermentadores de aço inoxidável, com aeração e agitação. Um inóculo é introduzido no reator e tem-se início o período de crescimento do microrganismo, que varia entre 17 e 48 horas. A temperatura ótima para o crescimento celular é entre 27 e $37{ }^{\circ} \mathrm{C}$ e o meio de cultura contém níveis nutricionais mínimos para facilitar a extração e purificação do produto fermentado.

Após atingir a concentração de células desejada, o substrato é adicionado ao fermentador e tem-se início as transformações sob as mesmas condições. Esteroides são pouco solúveis ou insolúveis em água. Logo, o substrato é dissolvido em solvente miscível em água (propilenoglicol, etanol, metanol, acetona, dimetil-sulfóxido, dimetilformamida) para facilitar a remoção de produto. A alimentação de substrato pode ser contínua ou semicontínua, sendo esta última interessante por minimizar os efeitos tóxicos dos solventes sobre os microrganismos, seguida de forte agitação para favorecer as transformações e a formação de cristais.

Uma forma de evitar o contato do microrganismo com o solvente é adicionar o substrato na forma sólida finamente dividido.

O processo de transformação através de enzimas ocorre durante um período de tempo entre 24 e 48 horas, em temperatura em torno de $30{ }^{\circ} \mathrm{C}$ e sob baixa aeração.

Ao finalizar as transformações, o meio de cultura é filtrado para recuperação do produto. Solvente imiscível em água (cloreto de etila, clorofórmio, acetato de etila) é utilizado para extrair o produto. Após a evaporação do solvente, o produto é separado como pó ou óleo e será submetido a etapas de cristalização a fim de se obter um produto puro.

Processo de fermentação dupla: A etapa de crescimento de microrganismo é semelhante ao processo anterior, com diferença apenas do meio nutritivo que é mais rico para favorecer o crescimento. Após atingir a concentração de células desejada, o microrganismo é separado do meio de cultura através de filtração ou centrifugação. O 
microrganismo é lavado para retirada de nutrientes e mantido em suspensão em meio volume de água destilada, solução fisiológica ou em um tampão.

O substrato dissolvido em solvente é adicionado ao meio contendo os microrganismos e a transformação acontece em algumas horas, sob aeração e agitação, em temperatura em torno de $30{ }^{\circ} \mathrm{C}$.

Ao finalizarem as transformações, o produto é extraído de maneira semelhante à descrita no processo anterior.

Neste processo, o tempo de duração das transformações é menor e o controle das mesmas é favorecido; o custo com aparelhagem é menor; e a maior facilidade na extração das células permitem que estas sejam reutilizadas.

O consumo de hormônios esteroides sintéticos tem aumentado a medida que são descobertos novos usos clínicos destas substâncias. Porém, a excreção de alguns deles, como o 17 $\alpha$-etinilestradiol, tem causado sérios problemas ambientais.

\subsection{HORMONIOS ESTEROIDES E SUAS INFLUENCIAS NO MEIO AMBIENTE}

Segundo Girotto et al. (2007), os hormônios esteroides naturais, como o $17 \beta$ estradiol, a estrona e o estriol, e os hormônios esteroides sintéticos, como o $17 \alpha$ etinilestradiol, têm despertado grande interesse da comunidade científica devido à presença dos mesmos em águas despejadas em rios, inclusive, após tratamento. Atualmente, Cunha et al. (2016) destacam o tema como de grande relevância ambiental devido aos prejuízos que a presença destes compostos na água podem causar à população animal e humana.

Cunha et al. (2016) classificam estes compostos como desreguladores endócrinos, que, por sua vez, são um grupo de substâncias que se classificam como micropoluentes. Micropoluentes são classificados pelos mesmos autores como compostos orgânicos e inorgânicos que se apresentam em concentrações baixas da ordem de $\mu \mathrm{g} . \mathrm{L}^{-1}$ e ng. $\mathrm{L}^{-1}$ e ainda assim são capazes de provocar danos à saúde animal e humana. Existe uma grande diversidade de compostos micropoluentes, naturais ou sintéticos. A Tabela 2 apresenta diversos compostos classificados como desreguladores endócrinos. 
Tabela 2 - Exemplos de compostos desreguladores endócrinos

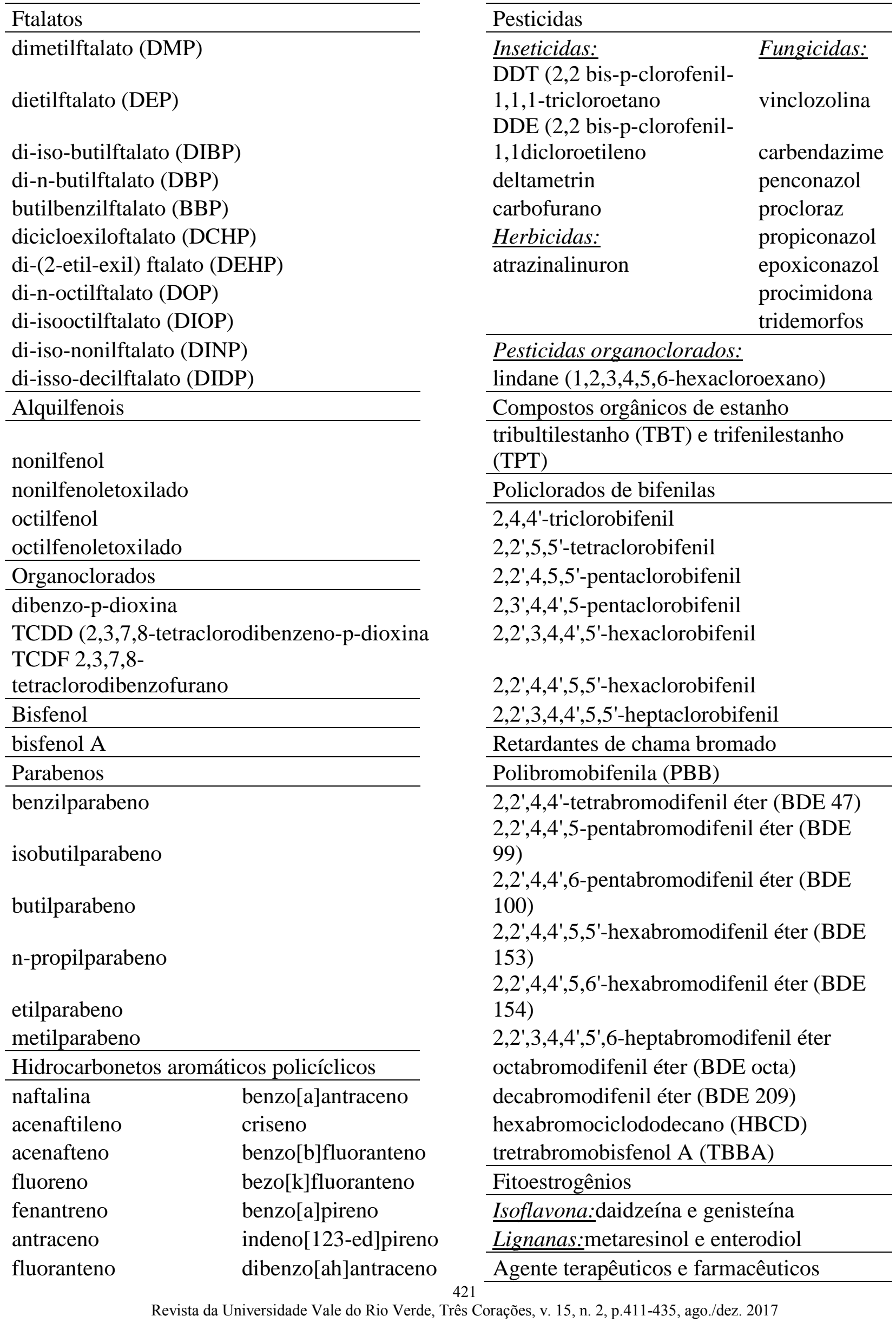




\begin{tabular}{ll} 
pireno & benzo[ghi]perileno \\
\hline Metais pesados & \\
\hline cádmio \\
mercúrio \\
chumbo \\
zinco \\
\hline Fonte: Bila e Dezotti, 2007
\end{tabular}

Fonte: Bila e Dezotti, 2007

Bila e Dezotti (2007) definem os desreguladores endócrinos como compostos químicos que estão presentes no meio ambiente em concentrações da ordem de $\mu g . L^{-1}$ e ng. $L^{-1}$ e que podem interferir no sistema endócrino de animais e humanos. Em animais, podem provocar feminização de peixes machos; alterações no sistema imunológico de mamíferos marinhos; diminuição na eclosão de ovos de peixes, dietilbestrol (DES)

17 $\alpha$-etinilestradiol (EE2)

Estrogênios naturais

estrona (E1)

$17 \beta$-estradiol (E2)

tartarugas e pássaros; problemas reprodutivos em pássaros, peixes, répteis e mamíferos, podendo, até mesmo, levar ao declínio da população. Em humanos, podem ser a causa da diminuição do esperma, aumento da incidência de câncer de mama, próstata e testículos e, ainda, provocar endometriose. A Tabela 3 mostra o efeito do $17 \alpha$-etinilestradiol s em diversas espécies.

Tabela 3 - Efeito do $17 \alpha$-etinilestradiol em diversas espécies

Espécie/Fase da vida do organismo no início do teste

Efeitos observados

Peixes

Daniorerio

Embriões

Alteração no comportamento de acasalamento; Indução da síntese de vitelogenina em machos; anomalias e mortalidade de mebriões

Machos e fêmeas adultos Alterações histopatológicas nas fêmeas

Adultos machos Diferentes estágios

Indução da síntese de vitelogenina e alterações no comportamento

Indução da síntese de viteloginina; Atraso e redução da desova; Redução das taxas de fertilização

Oryziaslatipes

Embriões

Adultos machos

Redução significativa ma taxa de fertilização

Um dia após o nascimento Indução da síntese vitelogenina e feminização Mudança significativa na proporção de sexos (mais fêmeas) e hermafroditismo

Oryziasmelastigma

Machos e fêmeas adultos

Alteração no comportamento de acasalamentos e inibição da desova 
Pimephalespromelas

Embriões

Adultos machos

Bettasplendens

Machos e fêmeas jovens e adultos

Pomatoschistusminutus

Adultos machos

Gasterosteusaculeatus

Adultos machos

Gobiocyprisrarus

Machos e fêmeas adultos

Anfíbios

\section{Xenopuslaevis}

Adultos machos

Hylellaazteca

4 a 6 semana a partir da

gametogênese

\section{Gammaruspulex}

Diferentes estágios

Crustáceos

\section{Daphnia magna}

Larva

Ceriodaphniareticulata

Larva

Sida crystallina

Larva
Diminuição do tamanho do corpo e indução da síntese de vitelogenina; Diminuição da fertilização dos ovos e feminização; Feminização, Inibição significativa da espermatogênese Alterações no comportamento reprodutivo, redução dos níveis hormonais e das características sexuais secundárias

Alteração no comportamento de acasalamento

Indução da síntese de vitelogenina e da proteína da zona radiada

Alteração no comportamento de acasalamento

Indução da síntese de vitelogenina em ambos os sexos; Alterações no fígado e nos rins; Feminização

Indução da síntese de vitelogenina e alterações hepáticas; Alteração no comportamento de acasalamento; Alterações significativas do comportamento

Redução do crescimento nos machos

Aumento significativo do tamanho médio populacional; Mudança na razão sexual dos adultos (2:1 em favor das fêmeas)

Diminuição do número de neonatos produzidos por fêmea

Aumento da mortalidade dos recém-nascidos 
Molusco

Lymneastagnalis

Ovos

Machos e fêmeas adultos

Porífero

\section{Hydravulgaris}

Machos e fêmeas adultos

Equinodermas

Hemicentrotuspulcherrimus/

Strongylocentrotusnudus

Embrião e larva
Atraso significativo da eclosão; Deformações nos caracóis em desenvolvimento; Redução do crescimento de filhotes

Alteração na reprodução
Reduções significativas do número de ovócitos (fêmea) e da atividade do esperma (macho)

Fonte: Cunha et al., 2016

Segundo Bila e Dezotti (2007), estes compostos são lançados no meio aquático a partir de efluentes de estações de tratamento de esgoto (ETE), uma vez que não é possível a remoção total destes compostos durante o tratamento, bem como a eliminação das respectivas atividades estrogênicas. Estações de tratamento de água (ETA) também não têm obtido sucesso na remoção destes compostos da água. A Figura 6 mostra uma possível rota destes compostos.

Figura 6 - Possível rota dos desreguladores endócrinos

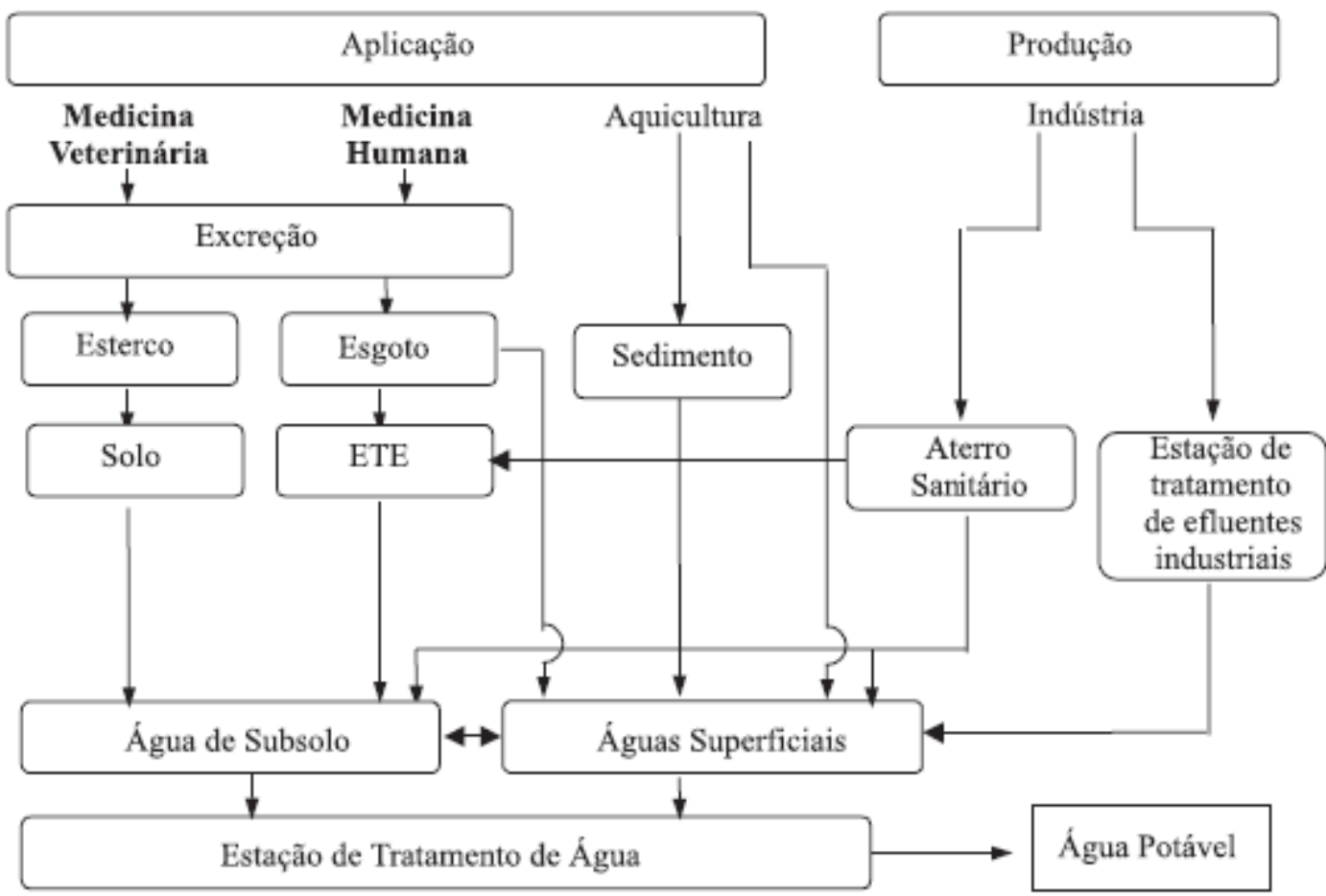

Fonte: Bila e Dezotti, 2003 
Tecnologias têm sido estudadas visando a remoção destes compostos da água e a eliminação de sua atividade estrogênica.

Em 2007, Bila et al. estudaram a degradação do esteroide natural $17 \beta$-estradiol e a remoção de sua atividade estrogênica através da ozonização em três diferentes pHs (3, 7 e 11). Concluíram que a ozonização é eficiente para remover o $17 \beta$-estradiol em soluções aquosas, mesmo utilizando baixas dosagens de ozônio. Porém, a atividade estrogênica não foi completamente removida, principalmente em $\mathrm{pH} 11$, em que a solução ainda apresentou alta atividade estrogênica. Acredita-se que este fato deve-se à oxidação via radicais $\mathrm{OH}$ formando produtos que possuem alta atividade estrogênica.

Em 2008, Maniero et al. investigaram a degradação do esteroide natural 17 $\beta$ estradiol e do esteroide sintético $17 \alpha$ etinilestradiol, bem como a remoção de suas atividades estrogênicas, através da ozonização e do processo oxidativo $\mathrm{O}_{3} / \mathrm{H}_{2} \mathrm{O}_{2}$ em três diferentes pHs (3, 7 e 11). Os processos oxidativos foram satisfatórios para remoção dos estrogênios em soluções aquosas, puros ou em mistura, apresentando remoção acima de $96 \%$ para todos os pHs trabalhados. A adição de $\mathrm{H}_{2} \mathrm{O}_{2}$ no processo de oxidação não trouxe melhores resultados. $\mathrm{Em} \mathrm{pH} \mathrm{3,} \mathrm{a}$ atividade estrogênica foi completamente removida, enquanto que em $\mathrm{pH} 7$ e 11 o mesmo não aconteceu. Acredita-se que os produtos formados pela oxidação via radical
$\mathrm{OH}$ possuem alta atividade estrogênica. A atividade estrogênica detectada foi maior no processo oxidativo via $\mathrm{O}_{3} / \mathrm{H}_{2} \mathrm{O}_{2}$.

Em 2011, Fernandes et al. trabalharam com a adsorção de $17 \beta$-estradiol e de $17 \alpha$ etinilestradiol em solução aquosa em turfa decomposta. De acordo com os autores, o processo de adsorção destes compostos pela turfa se mostrou eficiente, de modo que $76,2 \%$ de $17 \beta$-estradiol foi removido e $55,0 \%$ de $17 \alpha$-etinilestradiol. Os parâmetros termodinâmicos indicam que a adsorção destes compostos na turfa se dá de forma espontânea nas condições de experimento utilizadas. Os autores concluem que há perspectivas de utilizar este método para a remoção destes compostos de efluentes e de águas residuais.

Em 2015, Faria et al. estudaram a remoção de etinilestradiol e outros compostos de efluentes de reator anaeróbio de manta de lodo seguido de filtro biológico percolador (sistema UASB-FBP) em fotorreatores UV de lâmpadas emersas e imersas. Os resultados encontrados mostram que o processo de remoção estudado não foi efetivo para concentrações destes compostos da ordem de $\mu \mathrm{g} . \mathrm{L}^{-1}$.

Também em 2015, Lopes et al. investigaram a degradação do $17 \alpha$ etinilestradiol em solução aquosa ao utilizar um reator fotocatalítico heterogêneo, utilizando $\mathrm{TiO}_{2}$ como catalisador, em batelada com radiação ultravioleta. Os autores 
concluíram que o processo pode ser eficiente, embora dependa da concentração inicial do composto. A eficiência do processo também está atrelada à concentração de catalisador e à interação da concentração inicial do composto com a concentração de catalisador.

A questão da presença de compostos com atividade estrogênica em efluentes de estações de tratamento, e, consequentemente, presentes no habitat de diversas espécies e na água de consumo humano, ainda não foi resolvida. Pesquisadores da área estão procurando processos que sejam capazes de solucionar o problema. Espera-se que o processo viável seja encontrado em breve para que cessem os prejuízos causados por estes compostos.

\section{NOVAS PERSPECTIVAS}

Segundo Lima et. al. (2005), as expectativas para a produção industrial de esteroides giram em torno do desenvolvimento de tecnologias de imobilização de microrganismos, de sistemas de fases reversas para a transformação de substratos insolúveis em água e a tecnologia do DNA recombinante.

\subsection{Imobilização celular}

Segundo Covizzi et al. (2007), a imobilização de microrganismos, também chamada de imobilização celular, se dá quando há confinamento físico de células em um espaço definido, de forma que sejam mantidas suas funções catalíticas em processos contínuos ou descontínuos permitindo o reaproveitamento das mesmas.

A imobilização celular pode ser utilizada tanto em processos fermentativos de escala laboratorial como em processos de escala industrial. A Tabela 4 apresenta diversos processos em que a imobilização celular pode ser utilizada. A produção de esteroides tratase de uma biotransformação, como já citado anteriormente. 
Tabela 4 - Processos biotecnológicos que utilizam microrganismos imobilizados.

\begin{tabular}{|c|c|c|}
\hline Processo & Microrganismo & Suporte utilizado \\
\hline \multirow{2}{*}{$\begin{array}{l}\text { Produção } \\
\text { pigmentos }\end{array}$} & de $M$. purpureus & Alginato, PUF, carvão, perlita \\
\hline & G. fujikuroi & aginato \\
\hline $\begin{array}{l}\text { Produção } \\
\text { proteínas }\end{array}$ & de S. cerevisiae & PVA \\
\hline
\end{tabular}

\begin{tabular}{lll}
\hline Produção de & L. rhamnosus
\end{tabular}

exopolissacarídeos

Beijerinckia sp. $\quad$ Maltodextina
A. pullulans
Agar, algnato

\begin{tabular}{|c|c|c|}
\hline \multirow[t]{8}{*}{ Produção de enzimas } & N. frowardii & PUF \\
\hline & H. lutea & PVA-MAA/PEG; \\
\hline & & MAA/alginato de cálcio \\
\hline & Aspergillus sp. & CrioPAG $^{\circledR}$ \\
\hline & P. chrysosporium & $\begin{array}{l}\text { PUF, aço inoxidável, cerâmica, } \\
\text { náilon, poliestireno }\end{array}$ \\
\hline & Agaricus sp. & PUF \\
\hline & A. niger & alginato \\
\hline & P. ostreatus & PUF \\
\hline \multirow[t]{2}{*}{ Biotransformação } & R. minuta & $\begin{array}{l}\text { agar, clara de ovo, lã de } \\
\text { vidro/PEI }\end{array}$ \\
\hline & T. versilocor & náilon \\
\hline
\end{tabular}


Rhodococcus sp.

alginato

$\begin{array}{ll}\text { Biodegradação } & \text { Alginato, PUF } \\ \text { F. trogii } & \text { Alginato } \\ \text { P. stutzeri } & \text { Alginato, areia, } \\ & \text { carvão } \\ \text { E. coli e B. subtilis } & \text { Auto-imobilização } \\ \text { P. chrysosporium } & \text { PUF, cerâmica, } \\ & \text { serragem }\end{array}$

Rhodococcus sp.

Alginato, carvão

\begin{tabular}{lll}
\hline Redução de sulfatos & Bactérias & PUF, PE, Al2O3 \\
\hline Fermentação & S. cerevisiae & maçã \\
demostos de uvas & & \\
\hline
\end{tabular}

Produção de vinhos $K$. marxianus maçã

doces

Produção de leite L. casei alginato, maçã

fermentado

Produção de ácido L. casei bucha vegetal

lático

\begin{tabular}{|c|c|c|}
\hline Produção de sorbitol & Z. mobilis & bucha vegetal \\
\hline Produção de etanol & S. cerevisiae & bucha vegetal \\
\hline $\begin{array}{ll}\text { Produção } & \text { de } \\
\text { antibióticos } & \end{array}$ & S. clavuligerus & alginato, náilon \\
\hline
\end{tabular}

melanoidinas

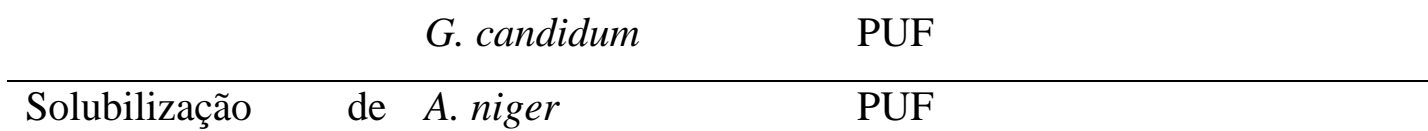

fosfatos

Chlorella spp. , e A. co-imobilização

brasilense 


Produção de M. anisopliae auto-imobilização
peptídeos para
controle de pragas

Produção de auxina e P. chrysosporium PUF

ácido abscísico

*PVA: álcool polivinílico; PUF: fibra de poliuretano; MAA: N-metileno acrilamida; PEG: polietilenoglicol; CrioPAG®:espuma de poliestireno não-trançada; PEI: polietilenoimina; PE: polietileno

Fonte: Covizzi et al., 2007

Covizzi et al. (2007) classificam as imobilizações celulares como natural ou artificial. As interações eletrostáticas entre o microrganismo e o suporte são responsáveis pelas imobilizações naturais, como a adsorção e a formação de biofilmes. Já nas imobilizações artificiais, como engaiolamento em matriz, os microrganismos se ligam ao suporte através de ligações covalentes.

Covizzi et al. (2007) definem alguns tipos de imobilização: a adsorção dos microrganismos é baseada na excreção de exopolissacarídeos com formação de biofilme e é um método de baixo custo, com diversos tipos de suportes e de fácil manipulação. O método de engaiolamento dos microrganismos aprisiona-os em malhas rígidas ou semi-rígidas, impedindo a difusão dos mesmos para o meio fermentativo, mas permitindo a troca de nutrientes, gases e metabólitos durante o processo. O método de floculação, um dos métodos mais promissores de imobilização de microrganismos, consiste na formação de aglomerados celulares na presença de agentes floculantes seguida de sedimentação natural. A Figura 7 ilustra diversos métodos de imobilização celular.

Figura 7 - Métodos de imobilização celular
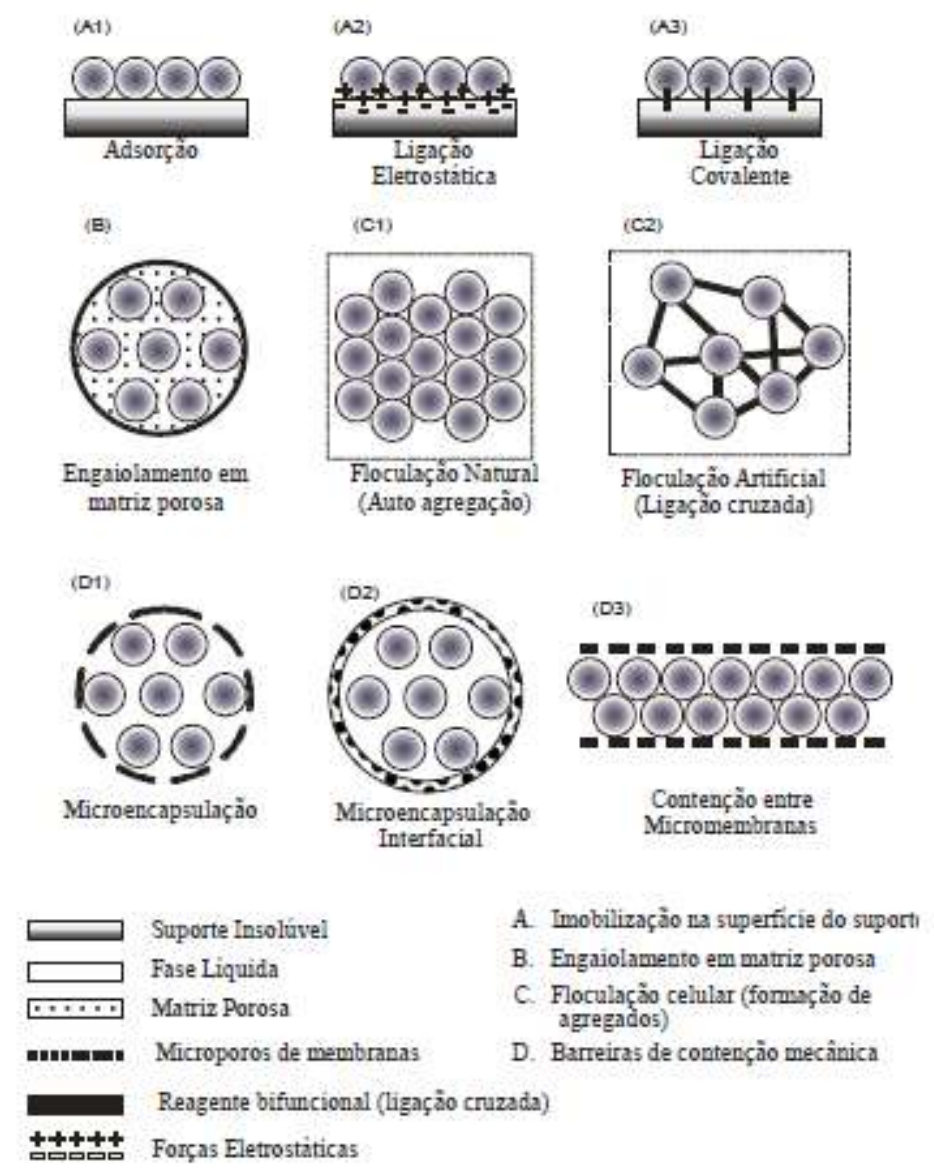

Fonte: Covizzi et al., 2007

De acordo com Canilha et al. (2006), a aplicação de células imobilizadas pode acontecer em três tipos de reatores, mostrados 
na Figura 8, que são: reatores de mistura, reatores de leito empacotado e reatores de leito fluidizado. Os reatores de mistura facilitam o controle das variáveis do processo e a transferência de oxigênio, mas devido à tensão de cisalhamento gerada pela agitação, os suportes contendo as células não oferecem grande resistência. Os reatores de leito empacotado apresentam baixo custo e são mais utilizados em processos anaeróbios, devido à dificuldade de transferência de oxigênio por todo o reator, prejudicando processos aeróbios. Os reatores de leito fluidizado são caracterizados pelas boas condições de mistura e pela baixa tensão de cisalhamento; é indicado que a diferença de densidade entre o meio fermentativo e o aglomerado celular seja a maior possível.

Figura 8 - Reatores com imobilização de células: (a) reator de mistura; (b) reator de leito empacotado; (c) reator de leito fluidizado
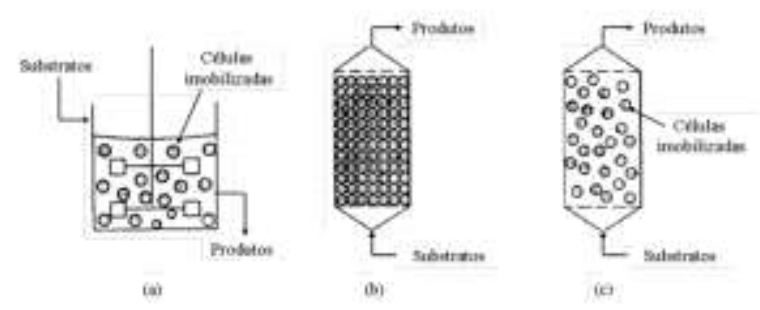

Fonte: Canilha et al., 2006

Em relação a processos fermentativos com células livres, processos com imobilização de microrganismos apresentam vantagens, apresentadas por Covizzi et al. (2007), como o aumento da produtividade devido ao aumento do número de células, a reutilização das células possibilitando processos contínuos sem reciclo, operações em condições adversas de $\mathrm{pH}$, esterilidade e agitação. Porém, como aponta Canilha et al. (2006), o estado fisiológico do microrganismo não pode ser controlado e a transferência de massa é prejudicada, alterando a cinética do crescimento celular e provocando o rompimento da matriz, como destacado por Covizzi et al. (2007).

\subsection{Sistemas de fase reversa}

Segundo Bicudo (2007), a cromatografia em fase líquida é uma técnica de análise e separação de substâncias baseada na migração diferencial de componentes de uma mistura, em que a amostra é transportada em uma fase móvel e forçada através de uma fase estacionária imiscível fixa em uma coluna ou superfície sólida. Neste sistema, a fase móvel apresenta baixa polaridade enquanto a fase estacionária apresenta alta polaridade, de forma que a fase móvel arrasta substâncias apolares contidas na amostra enquanto substâncias polares ficam retidas na fase estacionária.

De acordo com Tonhi (2002), na cromatografia líquida em fase reversa, a fase estacionária possui baixa polaridade e a fase móvel possui polaridade mais alta, de forma que a fase móvel seja mais polar que a fase estacionária. A cromatografia líquida de alta eficiência, conhecida por HPLC, utiliza sistema de fase reversa e tem sido um método 
de análise bastante difundido devido à boa sensibilidade e à possibilidade de separar espécies não voláteis e termicamente instáveis.

Como apresentado anteriormente, os substratos esteroides são dissolvidos em solventes miscíveis em água (polares) para a biotransformação e o produto é posteriormente extraído com solvente imiscível em água (apolar). De acordo com Lima et al. (2005), o sistema de fase reversa aplicado para as biotransformações nos processos de produção de esteroides consiste na dissolução de substratos esteroides pouco solúveis em água em solventes imiscíveis em água (orgânicos; apolares) para que aconteça a transformação. Este sistema apresenta algumas vantagens, como o rápido transporte dos substratos e produtos entre fases aquosa (polar) e orgânica (apolar) e maior solubilidade de oxigênio em solventes orgânicos para as biotransformações dependentes de oxigênio.

\subsection{Tecnologia do DNA recombinante}

De acordo com Nascimento et al. (2003), uma molécula de DNA recombinante possui sequências de diferentes fontes. A formação de uma molécula recombinante está diretamente relacionada com a ação das enzimas de restrição. As enzimas de restrição são classificadas de acordo com a estrutura, a atividade, os sítios de reconhecimento e o tipo de clivagem.
Nascimento et al. (2003) explicam que as enzimas de restrição fragmentam a molécula de DNA de forma que as extremidades das fitas simples permitam ligação com outras sequências de DNA. Estas enzimas possuem ação altamente específica, reconhecendo uma sequência única de bases e gerando uma família única de fragmentos quando clivam uma mesma molécula de DNA. A enzima DNA ligase realiza a ligação entre os diferentes fragmentos de DNA. A Figura 9 exemplifica a formação de uma molécula recombinante a partir de fragmentos do DNA humano e do plasmídeo de uma bactéria.

Figura 9 - Exemplificação da formação de uma molécula recombinante

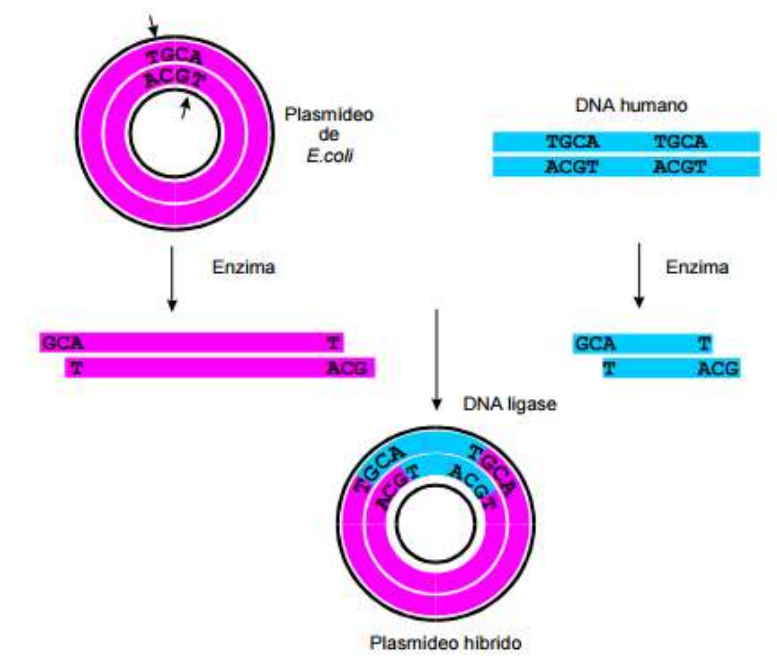

Fonte: Nascimento et al., 2003

Para a produção industrial de esteroides, interessa a clonagem de um único microrganismo que contenha todos os genes necessários para todas as reações envolvidas na biotransformação, reduzindo a apenas uma etapa todo $\mathrm{o}$ processo de conversão do 
substrato no produto final. $\mathrm{O}$ desenvolvimento desta tecnologia otimizaria o processo e reduziria os custos de produção, permitindo a comercialização de produtos mais atrativos no mercado.

\subsection{Substituição do $17 \alpha$-etinilestradiol}

Outra expectativa do setor é que a indústria farmacêutica substitua o $17 \alpha-$ etinilestradiol por outro composto. Espera-se que o composto de substituição não seja classificado como micropoluente e que não cause efeitos adversos à saúde animal e humana como os efeitos causados pelas pequenas concentrações de $17 \alpha-$ etinilestradiol.

\section{CONCLUSÃO}

Com o presente trabalho, é possível concluir que a produção industrial de hormônios esteroides é imprescindível para o melhoramento da qualidade de vida humana. Logo, o estudo em busca da otimização do processo deve ser constante, desde a seleção do microrganismo e do substrato, ao processo fermentativo adequado e ao desenvolvimento de tecnologias que favoreçam o processo.

A busca de novas tecnologias deve ainda se preocupar com o tratamento de efluentes que possam conter compostos com ação estrogênica, como é o caso do $17 \beta$-estradiol e do $17 \alpha$-etinilestradiol É importante conhecer o impacto ambiental que as substâncias produzidas podem causar, buscando sempre alternativas que minimizem os impactos negativos.

\section{REFERÊNCIAS}

SOARES, P. H. dos S. Reações de adição conjugada em esteroides - aplicação a potenciais agentes quimioterápicos. 2013. 74 f. Dissertação (Mestrado em Ciências Farmacêuticas) - Universidade da Beira Interior, Corvilhã, 2013. Disponível em: < http://ubibliorum.ubi.pt/handle/10400.6/1353>. Acesso em: 05 Jul 2016.

AMADEI, S. U. et al. A influência da deficiência estrogênica no processo de remodelação e reparação óssea. J. Bras. Patol. Med. Lab., Rio de Janeiro, v. 42, n. 1, p. 5-12, Feb. 2006. Disponível em:

$<$ http://www.scielo.br/scielo.php?script=sci_artt ext\&pid=S1676$24442006000100003 \& \operatorname{lng}=e n \& n r m=i s o>$. Acesso em: 05 Jul 2016.

ANTONOW, D. R. et al. Glicorticoides: uma meta-análise. Disc. Scientia. Série: Ciências da Saúde, Santa Maria, v. 8, n. 1, p. 51-68, 2007. Disponível em: < http://www.periodicos.unifra.br/index.php/disci plinarumS/article/view/918/862>. Acesso em: 05 Jul 2016.

DE OLIVEIRA, L. G.; MANTOVANI, S. M. Transformações biológicas: contribuições e perspectivas. Quim. Nova, v. 32, n. 3, p. 742756, 2009. Disponível em: <http://unicamp.sibi.usp.br/handle/SBURI/2384 2>. Acesso em: 07 Jul 2016.

NELSON, D. L.; MICHAEL, M. C. Princípios de Bioquímica de Lehninger. 6 ed. Porto Alegre: Artmed Editora, 2014.

VOET, D.; VOET, J. G. Bioquímica. 4 ed. Porto Alegre: Artmed Editora, 2013. 1481 p.

PATRICIO. Colesterol: Importancia y Funciones. Química y algo más, Mai 2011. Disponível em: <http://www.quimicayalgomas.com/salud/colest 
erol-importancia-y-funciones/>. Acesso em: 06 Jul 2016.

REDONDO, F. R. R. Efeitos do uso de esteróides anabolizantes associados ao treinamento físico de natação sobre o fluxo sangüíneo para o miocárdio de ratos normotensos. 2007. Dissertação (Mestrado em Biodinâmica do Movimento Humano) - Escola de Educação Física e Esporte, Universidade de São Paulo, São Paulo, 2007. Disponível em: <http://www.teses.usp.br/teses/disponiveis/39/3 9132/tde-20042007-100232/>. Acesso em: 06 Jul 2016.

VIGO, F. et al. Progestógenos: farmacologia e uso clínico. FEMINA, v. 39, n 3, Mar. 2011.

Disponível em:

<http://files.bvs.br/upload/S/0100-

7254/2011/v39n3/a2498.pdf >. Acesso em: 05 Jul 2016.

RATHKE, A. F. et. al. Contracepção hormonal contendo apenas progesterona.

AdolescenciaLatinoamericana, 1414-7130/2, p. 90-96, 2001. Disponível em: < http://redece.org/Contracepcaohormonal2014.p df>. Acesso em: 05 Jul 2016.

FERNADES, R. P. S. Contracepção oral como agente etiológico na cancerização humana. 2015. 90 f. Dissertação (Mestrado em Ciências Farmacêuticas) - Instituto Superior de Ciências da Saúde Egas Moniz, 2015. Disponível em: < https://comum.rcaap.pt/bitstream/10400.26/109 58/1/Fernandes\%2c\%20Rui\%20Pedro\%20Sous a.pdf >. Acesso em: 06 Jul 2016.

BAVARESCO, L. et. al. Glicocorticóides: usos clássicos e emprego no tratamento do câncer. Informa, v. 17, n. 7/9, 2005. Disponível em: <http://www.revistas.cff.org.br/infarma/article/v iew/260>. Acesso em: 05 Jul 2016.

FERNANDES-ROSA, F. L.; ANTONINI, S. R. R. Resistência aos mineralocorticóides: pseudo-hipoaldosteronismo Tipo 1.

ArqBrasEndocrinol Meta, v. 51, n. 3, p. 373381, 2007. Disponível em: < http://www.scielo.br/pdf/abem/v51n3/a04v51n3 .pdf>. Acesso em: 05 Jul 2016.

MIRANDA, M.; FONTOURA, M.

Pseudohipoaldosteronismo tipo I na criança.
Arquivos de Medicina, v. 27, n. 6, p. 265-271, 2013. Disponível em: < http://www.scielo.gpeari.mctes.pt/pdf/am/v27n6 /v27n6a04.pdf>. Acesso em: 05 Jul 2016.

WANJGARTEN, M. et al. Abordagem das hipotensões ortostática e pós-prandial.

RevBrasHipertens, v. 14, n. 1, p. 29-32, 2007. Disponível em: <

http://departamentos.cardiol.br/dha/revista/141/08-abordagem-hipotensoes.pdf> Acesso em: 05 Jul 2016.

REIS FILHO, R. W. et al. Hormônios sexuais estrógenos: contaminantes bioativos. Quim Nova, v. 29, n. 4, p. 817-822, 2006. Disponível em: <

http://www.scielo.br/pdf/\%0D/qn/v29n4/30264. pdf >. Acesso em: 05 Jul 2016.

MACÊDO, M.M.; FERNANDES, F ${ }^{\circ}$.J. Estudo das características dermatoglíficas, somatotípicas e das qualidades físicas básicas nos diversos estágios de maturação sexual.

Fitness \& Performance Journal, v. 2, n. 6, p. 315-320, 2003. Disponível em: < http://fpjournal.org.br/painel/arquivos/17231_Maturacao_sexual_Rev6_2003_Portugues.pd f>. Acesso em: 05 Jul 2016.

IGNACIO, D. L. et al. Regulação da massa corpórea pelo estrogênio e pela atividade física. ArqBrasEndocrinolMetab, v. 53, n. 3, p. 310317, 2009. Disponível em:

<http://www.scielo.br/pdf/abem/v53n3/v53n3a0 3.pdf $>$. Acesso em: 05 Jul 2016.

PINTO, R. M. de A.; CHIAPETA, S. M. S. V. $\mathrm{O}$ cálcio, o estrogênio e a atividade física na intervenção da osteoporose em mulheres no climatério. Rev. min. Educ. Fis., Viçosa, MG, v. 3, n. 2, p. 5- 16, 1995. Disponível em: < http://www.revistamineiradeefi.ufv.br/artigos/ar quivos/a8f34bb4cd13873d4da93b5cee3a8ebe.p df>. Acesso em: 05 Jul 2016.

GIACOMINI, D. R.; MELLA, E. A. C. Reposição Hormonal: vantagens e desvantagens. Semina: Ciências Biológicas e Saúde, Londrina, v. 27, n. 1, p.71-92, jan./jun. 2006. Disponível em:

<http://www.uel.br/revistas/uel/index.php/semi nabio/article/view/3530>. Acesso em: $05 \mathrm{Jul}$ 2016. 
ZAHAR, S. E. V. et. al. Qualidade de vida em usuárias e não usuárias de terapia de reposição hormonal. RevAssocMedBras, v. 51, n. 3, p. 133-138, 2005. Disponível em: <http://www.scielo.br/pdf/\%0D/ramb/v51n3/a1 2v51n3.pdf>. Acesso em: 06 Jul 2016.

PARDINI, D. Terapia de reposição hormonal na menopausa. ArqBrasEndocrinolMetab., 58/2, p. 172-181, 2014. Disponível em: <http://dx.doi.org/10.1590/00042730000003044>. Acesso em: 05 Jul 2016.

ROCHA, F. L. et al. Esteróides anabolizantes: mecanismos de ação e efeitos sobre o sistema cardiovascular. O Mundo da Saúde, São Paulo, v. 31, n. 4, p. 470-477, out/dez 2007. Disponível em: <http://www.saocamilosp.br/pdf/mundo_saude/56/02_esteroides.pdf $>$. Acesso em: 06 Jul 2016.

SILVA, P. R. P. Esteróides anabolizantes no esporte. RevBrasMed Esporte, v. 8, n. 6, Nov/Dez 2002. Disponível em: < http://www.scielo.br/pdf/rbme/v8n6/v8n6a05.p df>. Acesso em: $06 \mathrm{Jul} 2016$.

MACEDO, C. L. D. et al. Uso de esteróides anabolizantes em praticantes de musculação e/ou fisioculturismo. RevBrasMed Esporte, v. 4, n. 1, Jan/Fev 1998. Disponível em: <http://www.scielo.br/pdf/rbme/v4n1/a04v4n1> . Acesso em: 06 Jul 2016.

ABRAHIN, O. S. C.; SOUSA, E. C. Esteroides anabolizantes androgênicos e seus efeitos colaterais: uma revisão crítico-científica. Rev.

Educ. Fis/UEM, v. 24, n. 4, p. 669-679, 4. trim. 2013. Disponível em: <

http://www.scielo.br/pdf/refuem/v24n4/14.pdf>. Acesso em: 06 Jul 2016.

DE OLIVEIRA, K. B.; DE OLIVEIRA, B. H. Obtenção de substâncias bioativas através da biotransformação de produtos naturais. Revista Eletrônica de Farmácia, v. 9, n. 1, p. 89 - 99, 2012. Disponível em: < https://revistas.ufg.br/REF/article/view/17777/1 0636>. Acesso em: 06 Jul 2016.

DE CASTRO, H. F. et al. Modificação de óleos e gorduras por biotransformação. Quim. Nova, v. 27, n. 1, p. 146-156, 2004. Disponível em: <
http://www.scielo.br/pdf/\%0D/qn/v27n1/18823. pdf >. Acesso em: 06 Jul 2016.

LIMA, U. de A. et al. Biotecnologia industrial: processos fermentativos e enzimáticos. 1 ed. São Paulo: Editora Edgard Blücher, 2005. 593 p.

AGUIAR, A. et al. Mecanismo e aplicações da reação de Fenton assistida por compostos fenólicos redutores de ferro. Quim. Nova, v. 30, n. 3, p. 623-628, 2007. Disponível em: <http://www.scielo.br/pdf/\%0D/qn/v30n3/22.pd f>. Acesso em: 06 Jul 2016.

DE CARVALHO, M. R. B. Avaliação da atividade dos inibidores de tripsina após digestão enzimática em grãos de soja tratados termicamente. Rev. Nutr., Campinas, v. 15, n. 3, p. 267-272, set./dez., 2002. Disponível em: < http://repositorio.unesp.br/handle/11449/4133>. Acesso em: 06 Jul 2016.

HINKE, N. El Barbasco. Ciencias 89, p. 54-57, enero-marzo 2008. Disponível em: <http://www.revistacienciasunam.com/es/46revistas/revista-ciencias-89/251-elbarbasco.html> . Acesso em: 06 Jul 2016.

GIROTTO, G. et al. Estrógenos em água: otimização da extração em fase sólida utilizando ferramentas quimiométricas. Eclética Química, São Paulo, v. 32, n 2, 2007.

Disponível em: <http://www.scielo.br/pdf/eq/v32n2/a10v32n2.p df $>$. Acesso em: 07 Jul 2016. DA CUNHA, D. L. et al. Regulamentação do estrogênio sintético $17 \alpha$-etinilestradiol em matrizes aquáticas na Europa, Estados Unidos e Brasil. Cad. Saúde Pública, Rio de Janeiro, v. 32, n. 3, e00056715, mar 2016. Disponível em: $<$ http://www.scielo.br/pdf/csp/v32n3/0102311X-csp-32-03-e00056715.pdf>. Acesso em: $04 \mathrm{Jul} 2016$.

BILA, D. M.; DEZOTTI, M. Desreguladores endócrinos no meio ambiente: efeitos e consequências. Quim. Nova, v. 30, n. 3, p. 651666, 2007. Disponível em: <http://www.scielo.br/pdf/qn/v30n3/26.pdf >. Acesso em: 04 Jul 2016.

BILA, D. M.; DEZOTTI, M. Fármacos no meio ambiente. Quim. Nova, v. 26, n. 4, p. 523-530, 
2003. Disponível em: <

http://www.scielo.br/pdf/qn/v26n4/16435.pdf>. Acesso em: 07 Jul 2016.

BILA, D. et al. Estrogenic activity removal of $17 \mathrm{~b}$-estradiol by ozonation and identification of by-products. Chemosphere, 69, p. 736-746, 2007. Disponível em: <http://www.sciencedirect.com/science/article/p ii/S0045653507006303>. Acesso em: 04 Jul 2016.

MANIERO, M. G. et al. Degradation and estrogenic activity removal of $17 \beta$-estradiol and $17 \alpha$-ethinylestradiol by ozonation and $\mathrm{O} 3 / \mathrm{H} 2 \mathrm{O} 2$. Science of the total environment, 407, p. 105-115, 2008. Disponível em: <http://www.sciencedirect.com/science/article/p ii/S0048969708008280>. Acesso em: 04 Jul 2016.

FERNANDES, A. N. et al. Remoção dos hormônios 17b-estradiol e 17a-etinilestradiol de soluções aquosas empregando turfa decomposta como material adsorvente. Quim. Nova, v. 34, n. 9, p. 1526-1533, 2011. Disponível em: < http://www.scielo.br/pdf/qn/v34n9/v34n9a09.pd f>. Acesso em: 04 Jul 2016.

DE FARIA, E. et al. Uso de fotorreatores UV para a remoção de diclofenaco, bezafibrato e etinilestradiol de esgoto tratado em sistema UASB-FBP. EngSanitAmbient, v.20, n.3, p. 493-502, jul/set 2015. Disponível em: < http://www.scielo.br/pdf/esa/v20n3/1413-4152esa-20-03-00493.pdf>. Acesso em: 04 Jul 2016.

LOPES, W. S. et al. Degradation of $17 \alpha-$ ethinylestradiol in water by heterogeneous photocatalysis. Rev. Ambient. Água, Taubaté, v.10, n. 4, Oct. / Dec. 2015. Disponível em: <http://www.scielo.br/pdf/ambiagua/v10n4/198 0-993X-ambiagua-10-04-00728.pdf >. Acesso em: 04 Jul 2016.

COVIZZI, L. G.; GIESE, E. C.; GOMES, E.; DEKKER, R. F. H.; SILVA, R. Imobilização de células microbianas e suas aplicações biotecnológicas. Semina: Ciências exatas e tecnológicas, Londrina, v. 28, n. 2. p. 143-168, , 2007. Disponível em: < http://www.uel.br/proppg/portal/pages/arquivos/ pesquisa/semina/pdf/semina_28_2_22_32.pdf >. Acesso em: 06 Jul 2016.

CANILHA, L.; CARVALHO, W.; SILVA, J. B. de A. Biocatalisadores imobilizados: uso de células e enzimas imobilizadas em processos biotecnológicos. Biotecnologia Ciência \& Desenvolvimento, n. 36, p. 48-57, 2006. Disponível em: < http://www.biotecnologia.com.br/revista/bio36/ biocatalizadores_36.pdf>. Acesso em: $06 \mathrm{Jul}$ 2016.

TONHI, E. et al. Fases estacionárias para cromatografia líquida de alta eficiência em fase reversa (clae-fr) baseadas em superfícies de óxidos inorgânicos funcionalizados. Quim Nova, v. 5, n 4, p. 616-623, 2002.

BICUDO, R. C. Avaliação de sistemas de cromatografia líquida uni e bidimensional acoplados a espectrometria de massas na análise de proteoma dos corpos proteicos do milho. 113 f. 2007. Tese (Doutorado em Ciências (Química Analítica)) - Universidade de São Paulo, São Carlos, SP, 2007.

NASCIMENTO, A. A. C. et al. Tecnologia do DNA recombinante. Universidade de São Paulo. Faculdade de Medicina de Ribeirão Preto. 2003. Disponível em: $<$ http://rbp.fmrp.usp.br/sites/default/files/apostil atd_2005.pdf>. Acesso em: 06 de Jul 2016. 